\title{
Administration of acetylsalicylic acid after parturition in lactating dairy cows under certified organic management: Part II. Biomarkers of nociception, inflammation, and stress
}

\author{
A. A. Barragan, ${ }^{1 *}$ L. M. Bauman, ${ }^{2}$ G. M. Schuenemann, ${ }^{1}$ J. Velez, ${ }^{3}$ J. Lakritz, ${ }^{4}$ J. F. Coetzee, ${ }^{5}$ \\ J. D. Rozo Gonzalez, ${ }^{3}$ J. M. Piñeiro, ${ }^{1}+$ B. Menichetti, ${ }^{1}$ and S. Bas ${ }^{1 *} \neq \S$ \\ ${ }^{1}$ Department of Veterinary Preventive Medicine, The Ohio State University, Columbus 43210 \\ ${ }^{2}$ Department of Animal Sciences, The Ohio State University, Columbus 43210 \\ ${ }^{3}$ Aurora Organic Farms, Platteville, CO 80651 \\ ${ }^{4}$ Department of Veterinary Clinical Sciences, The Ohio State University, Columbus 43210 \\ ${ }^{5}$ Department of Anatomy and Physiology, Kansas State University, Manhattan 66506
}

\section{ABSTRACT}

The objective was to assess the effect of oral administration of acetylsalicylic acid after calving on the concentrations of substance P (SP), haptoglobin (HP), and cortisol in lactating dairy cows. Holstein dairy cows (n $=152$ ) from 3 organic herds were included. At parturition, cows were blocked by parity [multiparous (MULT) and primiparous (PRIM)] and calving ease [eutocia (EUT) and dystocia (DYS)] and were randomly assigned to 1 of 2 treatment groups: aspirin (ASP; $\mathrm{n}=$ 76 ), in which within $12 \mathrm{~h}$ after parturition cows received 4 treatments with acetylsalicylic acid $(100 \mathrm{mg} / \mathrm{kg} ; 2$ boluses) at 12 -h intervals, or placebo (PLC; $\mathrm{n}=76$ ), in which within $12 \mathrm{~h}$ after parturition cows received 4 consecutive treatments with gelatin capsules (2 capsules) containing water $12 \mathrm{~h}$ apart. Blood samples were collected immediately before treatment and at 12, 24, 36, 48, and $168 \mathrm{~h}$ (7 DIM) for assessment of circulating concentration of SP, HP, and cortisol. Based on farm records, cows were classified in the following clinical disease categories: no clinical disease event (NO-EVT), a single clinical disease event (SI-EVT), and more than 1 clinical disease event (MU-EVT). The study data were analyzed as a randomized complete block design using mixed multiple linear and logistic regression models.

Received February 18, 2020.

Accepted July 21, 2020.

${ }^{*}$ Current address: Department of Veterinary and Biomedical Sciences, Pennsylvania State University, University Park 16802.

$\dagger$ Current address: Texas A\&M AgriLife Research and Extension Center, Amarillo 79106.

$\ddagger$ Current address: Phytobiotics Futterzusatzstoffe GmbH, D-65343 Eltville, Germany.

$\S$ Corresponding author: s.bas@phytobiotics.com
With regard to HP, there was a tendency for an interaction between treatment and parity, where MULT cows treated with ASP had lower concentration of HP compared with MULT cows treated with PLC (ASP = $124.33 \pm 6.83 \mu \mathrm{g} / \mathrm{mL} ;$ PLC $=143.9 \pm 7.24 \mu \mathrm{g} / \mathrm{mL})$. Analysis by calving ease showed that cows with DYS had higher concentrations of HP (DYS $=159.17 \pm 5.97$ $\mu \mathrm{g} / \mathrm{mL} ; \mathrm{EUT}=138.72 \pm 6.22 \mu \mathrm{g} / \mathrm{mL}$ ) and SP (only at $168 \mathrm{~h} ;$ DYS $=64.99 \mathrm{pg} / \mathrm{mL}, 95 \%$ confidence interval, CI: $2.68-2.81 ; \mathrm{EUT}=60.33 \mathrm{pg} / \mathrm{mL}, 95 \%$ CI: 2.91-3.06) after calving compared with EUT cows. Regardless of treatment, PRIM cows had higher concentrations of SP $(\mathrm{MULT}=55.11 \mathrm{pg} / \mathrm{mL}, 95 \%$ CI: $1.27-1.30 ;$ PRIM $=$ $57.62 \mathrm{pg} / \mathrm{mL}, 95 \%$ CI: 1.99-2.06), HP (MULT $=134.14$ $\pm 4.96 \mu \mathrm{g} / \mathrm{mL} ;$ PRIM $=163.75 \pm 7.76 \mu \mathrm{g} / \mathrm{mL})$, and cortisol (MULT $=18.65 \mu \mathrm{g} / \mathrm{mL}, 95 \%$ CI: $1.02-1.05$; PRIM $=21.92 \mu \mathrm{g} / \mathrm{mL}, 95 \%$ CI: 1.67-1.74) compared with MULT cows. In addition, cows that experienced SI-EVT or MU-EVT had higher concentrations of HP $(\mathrm{NO}-\mathrm{EVT}=134.13 \pm 5.95 \mu \mathrm{g} / \mathrm{mL} ;$ SI-EVT $=142.68$ $\pm 7.32 \mu \mathrm{g} / \mathrm{mL} ;$ MU-EVT $=170.03 \pm 9.42 \mu \mathrm{g} / \mathrm{mL})$ and cortisol (NO-EVT $=17.86 \mu \mathrm{g} / \mathrm{mL}, 95 \%$ CI: $1.20-1.24$; SI-EVT $=21.01 \mu \mathrm{g} / \mathrm{mL}, 95 \%$ CI: 1.61-1.67; MU$\mathrm{EVT}=22.01 \mu \mathrm{g} / \mathrm{mL}, 95 \%$ CI: 2.08-2.18) compared with cows with NO-EVT recorded. Results from this study suggest that a short-duration anti-inflammatory therapy after calving reduced HP in MULT cows but may not have effects on SP and cortisol concentrations. Calving ease and parity affected the concentrations of markers of inflammation, nociception, and stress regardless of treatment. Further research is warranted to assess anti-inflammatory strategies aimed at decreasing inflammation and stress in DYS and PRIM cows and therefore improve welfare and performance of these high-priority groups.

Key words: calving, nonsteroidal anti-inflammatory drug, substance P, haptoglobin 


\section{INTRODUCTION}

Parturition is a natural process that progresses gradually from one stage to the next. However, severe dystocia (DYS), known as a calving difficulty resulting from prolonged or assisted calf extraction, has been categorized as one of the most painful events in dairy cattle (Huxley and Whay, 2006). Under normal conditions, inflammation is involved in the process of parturition (Norman et al., 2007). A growing body of research has shown that periparturient cows experience various degrees of inflammation that affect animals systemically (generalized inflammatory response; Sordillo et al., 1995; Trevisi et al., 2012). Bertoni et al. (2008) classified cows into inflammatory quartiles based on circulating concentrations of negative acute phase proteins as well as other metabolites, such as cholesterol, during the first month of lactation and observed that cows with the strongest inflammatory profile had reduced milk yield and more transition disorders. Inflammation should be regarded as an energetically costly process. Kvidera et al. (2017a,b) reported that after a lipopolysaccharide challenge, glucose requirements to maintain euglycemia were increased compared with nonchallenged controls. Thus, the increased energy demands associated with inflammation coupled with the reduction in DMI can exacerbate the predisposition of cows to metabolic and infectious disorders at the onset of lactation.

Assessment of inflammation and pain in cattle has focused on the measurement of physiological and behavioral changes (Coetzee, 2011; Theurer et al., 2013). In dairy cows, haptoglobin (HP) has been proposed as a marker of inflammation in lactating cows experiencing diseases such as metritis (Barragan et al., 2018), mastitis (Eckersall et al., 2001), and lameness (Smith et al., 2010) as well as a predictor of postpartum metritis (Huzzey et al., 2009). Cortisol has been extensively studied as an indicator of stress following dehorning and castration in calves (Coetzee, 2011). Furthermore, DYS has been associated with increased cortisol concentrations in dairy cows (Vannucchi et al., 2015). More recently, substance P (SP) has emerged as a marker for inflammation and nociception in farm animals (Stock et al., 2013). This 11-AA neuropeptide released from the dorsal horn of the spinal cord is associated with the transmission and modulation of pain and the integration of stress and anxiety (DeVane, 2001). Recently, Barragan et al. (2018) evaluated SP as an indicator of pain and inflammation in dairy cows and observed higher SP concentrations in cows with clinical metritis compared with cows without metritis. Although administration of nonsteroidal anti-inflammatory drugs (NSAID) appears to reduce SP concentrations after painful conditions, such as dehorning (Allen et al., 2013), further research is needed to determine the efficacy of these drugs on SP concentrations in adult cattle undergoing painful events, such as calving.

Strategies to minimize the negative effects associated with postpartum inflammation and pain are required to improve health, welfare, and performance of dairy cattle. Nonsteroidal anti-inflammatory drugs have been extensively studied as an alternative to mitigate inflammation early in lactation. However, postpartum inflammation is needed for physiological processes in the cows, such as placenta detachment, and previous research has shown that treatment with potent NSAID, such as meglumine flunixin, can impair these physiological processes (Newby et al., 2017). Acetylsalicylic acid (aspirin; ASP), a low-potency, inexpensive NSAID that is easy to administer, has also been proposed as an alternative to decrease postpartum inflammation, showing promising results. For instance, Farney et al. (2013b) reported that treatment of dairy cows with sodium salicylate in the drinking water during $7 \mathrm{~d}$ after parturition inhibited proinflammatory molecule production, such as TNF- $\alpha$, in the liver during the treatment period but increased others, such as thromboxane $\mathrm{B}_{2}, 7 \mathrm{~d}$ after treatment was finalized. Conversely, Carpenter et al. (2016) reported that treatment with sodium salicylate for $3 \mathrm{~d}$ after calving increased HP concentration in cows treated with ASP and meloxicam following parturition. However, the same research group (Carpenter et al., 2018) reported no difference in HP concentrations between treated cows and control cows. This inconsistency in findings, as well as the need to develop more applicable treatment therapy that fits day-to-day farm logistics, reflects the need for more applied research in these areas.

The objective of this study was to assess the effects of 4 ASP treatments administered $12 \mathrm{~h}$ apart after calving on biomarkers of nociception (SP), inflammation (HP), and stress (cortisol) in lactating dairy cows under certified organic management. Furthermore, as a secondary objective, data regarding clinical disease events were collected and the effects of clinical disease events on these biomarkers were assessed. We hypothesized that cows treated with ASP would have lower circulating concentrations of SP, HP, and cortisol compared with untreated animals.

\section{MATERIALS AND METHODS}

\section{Animals, Facilities, and Feeding}

The farm $(\mathrm{n}=3)$ description and main management practices (including pre- and postpartum rations) are described in a companion paper (Barragan et al., 2020). 
The Animal Care and Use Committee at The Ohio State University revised and approved the procedures described below (protocol no. 2016A00000045).

\section{Animal Enrollment and Allocation to Treatments}

Cows included in the present study were part of a larger trial (Barragan et al., 2020) and were retrospectively selected to be evenly distributed among groups based on parity, calving ease, and health events. Within $12 \mathrm{~h}$ after parturition cows were blocked by parity [primiparous (PRIM), n = 47; multiparous (MULT), $\mathrm{n}$ $=105]$ and calving ease [eutocia (EUT) or dystocia (DYS)] and were randomly allocated to 2 treatment groups: ASP $(\mathrm{n}=76)$ or placebo $(\mathbf{P L C} ; \mathrm{n}=76)$. Although cows were not selected considering BCS, there was no statistical difference in BCS at enrollment between treatment groups $(P=0.65 ; \mathrm{ASP}=3.08 \pm 0.04$; $\mathrm{PLC}=3.06 \pm 0.04)$. A total of $38 \mathrm{DYS}(\mathrm{PRIM}=13$; MULT $=25)$ and 38 EUT $($ PRIM $=11 ;$ MULT $=27)$ cows were included in the ASP group, whereas 38 DYS $(\mathrm{PRIM}=13 ; \mathrm{MULT}=25)$ and $38 \mathrm{EUT}(\mathrm{PRIM}=10$; MULT $=28$ ) cows were included in the PLC group. From herd A, 12 ASP and 12 PLC cows were selected. From herd B, $40 \mathrm{ASP}$ and 35 PLC were selected, and from herd C, 24 ASP and 29 PLC cows were selected. Calving difficulty was assessed using a 5 -point scale $(1=$ unassisted; $2=1$ person assisted; $3=2$ or more people assisted; $4=$ mechanical traction; $5=$ surgical procedure; Lombard et al., 2007). Cows with a calving difficulty score of $\leq 2$ were considered to have experienced eutocic births, whereas cows with a calving difficulty score of $\geq 3$ were categorized as having experienced DYS. Animals with a calving ease score of 5 were not included in the study. Cows in the ASP group received 4 consecutive treatments at approximately 12 -h intervals with acetylsalicylic acid $(100 \mathrm{mg} / \mathrm{kg} ; 2$ boluses of 960 grain; Agri Laboratories, St. Joseph, MO), and cows in the PLC group received 4 treatments approximately $12 \mathrm{~h}$ apart with gelatin capsules (2 capsules; Torpac Inc., Fairfield, NJ) filled with water. The first treatment was administered in the maternity facility, whereas the subsequent treatments were performed in the postpartum pens of the respective dairy farms.

\section{Cases of Diseases}

On-farm records (PCDART, North Carolina State University, Raleigh, NC) were collected to assess incidence of diseases during the first 60 DIM. Clinical disease events were recorded by the farm personnel [digestive disorders (cows with abnormal manure such as fluid or dry feces), lameness (cows that had difficulty walking normally; Van Nuffel et al., 2015), metritis (cows with red-brownish fetid and watery vaginal discharge; Barragan et al., 2018), endometritis (cows with purulent vaginal discharge after 21 DIM; Sheldon et al., 2008), pneumonia (cows that had difficulty breathing normally with pyrexia; Santos et al., 2011), and mastitis (cows that had abnormal milk in at least 1 of the quarters at milking; Santos et al., 2011)] and the research study team [retained placenta (lack of expulsion of the placenta within $24 \mathrm{~h}$ after calving; Noakes et al., 2001), subclinical ketosis (BHB concentration $>1.2$ $\mathrm{mmol} / \mathrm{L}$; Iwersen et al., 2009)]. Based on the number of recorded clinical disease events, lactating cows were classified in the following clinical disease categories: no clinical disease event (NO-EVT), a single clinical disease event (SI-EVT), and more than 1 clinical disease event (MU-EVT).

\section{Blood Sample Collection and Assessment of SP, HP, and Cortisol}

Blood samples for assessment of SP, HP, and cortisol were collected via coccygeal blood vessels immediately before each treatment administration $(12,24,36$, and $48 \mathrm{~h})$ and at $168 \pm 72 \mathrm{~h}(7 \pm 3 \mathrm{DIM})$ after parturition. Serum samples for determination of HP and cortisol were collected using 8.5-mL evacuated serum separator tubes (Vacutainer; Becton, Dickinson, and Co., Franklin Lakes, NJ). Samples for assessment of SP were collected into 7-mL evacuated tubes with K3 EDTA (Vacutainer) as previously described (Barragan et al., 2018). Briefly, $300 \mu \mathrm{L}$ of a solution containing $20 \mathrm{mM}$ benzamidine hydrochloride (Sigma-Aldrich, St. Louis, $\mathrm{MO})$ that acted as a protease inhibitor was added to each K3 EDTA before sample collection. The blood samples were stored on ice immediately after collection and were centrifuged $(15 \mathrm{~min}$ at $400 \times g$ at room temperature) within $2 \mathrm{~h}$ of collection to harvest plasma or serum, which was stored at $-20^{\circ} \mathrm{C}$ until further analysis.

Plasma SP concentrations were assessed using a competitive RIA technique with a double antibody system with a primary anti-cow SP (Phoenix Pharmaceuticals, Burlingame, CA) and 125I-SP (PerkinElmer Inc., Waltham, MA) antibody as previously described by Van Engen et al. (2014). The intra- and interassay coefficients of variation (CV) were 8.29 and $20.52 \%$, respectively. The analytical sensitivity of the assay was $10 \mathrm{pg} / \mathrm{mL}$. The concentrations of HP were determined with a commercially available bovine HP ELISA kit (Life Diagnostics, West Chester, PA) following the manufacturer's instructions. The CV for intra-assay variability was $3.21 \%$, and the interassay CV was 
$10.88 \%$. The analytical sensitivity of the assay was 3.91 $\mathrm{ng} / \mathrm{mL}$. Similarly, the concentration of cortisol was assessed with a commercially available RIA (Corti-Cote RIA kit, MP Biomedical, Irvine, CA) as previously described by Bates et al. (2014). The CV for intra- and interassay CV were 9.00 and $10.06 \%$, respectively, and analytical sensitivity of the assay was $0.625 \mathrm{ng} / \mathrm{mL}$.

\section{Statistical Analysis}

A power calculation was run to determine the required sample size for the present study. To be able to detect a difference of $10 \mathrm{pg} / \mathrm{mL}$ (Barragan et al., 2018) in circulating concentrations of SP between cows receiving ASP or PLC with adequate statistical power $(1-\beta=0.8)$ and statistical significance $(\alpha=0.05)$, a sample size of 71 dairy cows per group was required. The study was performed and analyzed as a complete randomized block design. The statistical analysis was performed using SAS statistical software (version 9.4, SAS Institute Inc., Cary, NC). The normality and homogeneity of variances for the quantitative variables were assessed through the UNIVARIATE procedure using Shapiro-Wilk statistic, graphical methods (histogram and quantile-quantile plot), and Bartlett's tests.

Continuous outcome variables were analyzed with the MIXED procedure of SAS. For analysis of SP, HP, and cortisol, the REPEATED statement was included in the MIXED procedure. In addition, because the first sample (i.e., $12 \mathrm{~h}$ ) for these biomarkers was collected immediately before treatment administration, the 12-h values were forced into these models as covariates to be used as baseline data between treatment groups (Montgomery et al., 2019). The covariate structures were selected using the best fit according to Schwarz's Bayesian information criteria. Selection of the variables that remained in the model was performed using the Wald statistic backward selection criterion $(P>0.15)$. The variable cow within farm was included in the RANDOM statement of the MIXED procedure. Furthermore, the variables hours after calving, treatment, treatment by hour after calving interaction, parity, and calving ease were forced in the models. The results are presented as least squares means and standard error of the mean, calculated and adjusted with the Tukey-Kramer method using the LSMEAN statement included in the MIXED procedure. When the interaction between treatment and hour after calving was significant $(P<0.05)$, the "slice" option in the "lsmeans" statement was used to determine differences among the treatments on each day. Due to lack of normal distribution, the variables SP and cortisol were $\log _{10}$ and square root transformed, respectively. The results of these variables were back transformed, and back-transformed geometric means and $95 \%$ confidence intervals were presented.

The variables originally offered to the models were 12 -h values, treatment, hour after calving, parity, calving ease, BCS at enrollment, BCS at $7 \pm 3$ DIM, study week, and clinical disease event as well as the 2-way interactions among these variables. For analysis of SP, the variables that remained in the model were 12 -h values, treatment, hour after calving, treatment by hour after calving interaction, parity, calving ease, and calving ease by time interaction. For the HP model, the variables 12 -h values, treatment, hour after calving, treatment by hour after calving interaction, parity, parity by hour after calving interaction, calving ease, clinical disease event, and clinical disease event by hour after calving interaction remained in the model. Last, the variables that remained in the cortisol model were 12-h values, treatment, hour after calving, treatment by hour after calving interaction, parity, parity by hour after calving interaction, calving ease, clinical disease event, and clinical disease event by hour after calving interaction. The main variables of interest and their interactions were considered statistically significant if $P$ $<0.05$, and $0.05 \leq P \leq 0.10$ was considered a tendency.

\section{RESULTS}

\section{Circulating Concentration of SP}

Circulating concentration of SP did not differ between treatments $(P=0.46 ; \mathrm{ASP}=56.76 \mathrm{pg} / \mathrm{mL}$, 95\% CI: $55.16-58.41 ;$ PLC $=55.95 \mathrm{pg} / \mathrm{mL}, 95 \%$ CI: $54.36-57.57)$. In both study groups, concentrations of SP gradually increased after parturition and reached the highest levels at $168 \mathrm{~h}$ (Figure 1a). Regardless of treatment, there was an interaction between calving ease and hour after calving $(P=0.07)$, where DYS cows had higher concentration of SP at $168 \pm 72 \mathrm{~h}$ after calving compared with EUT cows $(P=0.02$; DYS $=64.99 \mathrm{pg} / \mathrm{mL}, 95 \%$ CI: $62.08-68.06 ;$ EUT $=60.33$ pg/mL, 95\% CI: 57.65-63.15; Figure 1b). Furthermore, PRIM cows had higher circulating concentrations of SP compared with MULT cows regardless of treatment and calving ease $(P=0.04 ; \mathrm{PRIM}=57.62 \mathrm{pg} / \mathrm{mL}$, $95 \%$ CI: $55.62-59.68 ;$ MULT $=55.11 \mathrm{pg} / \mathrm{mL}, 95 \%$ CI: 53.83-56.42; Figure 1c). Concentrations of SP did not differ $(P=0.27)$ between cows with different number of clinical disease events.

\section{Circulating Concentration of HP}

There was no difference between treatment groups in $\mathrm{HP}$ concentration $(P=0.58 ; \mathrm{ASP}=146.38 \pm 6.11$ 
A

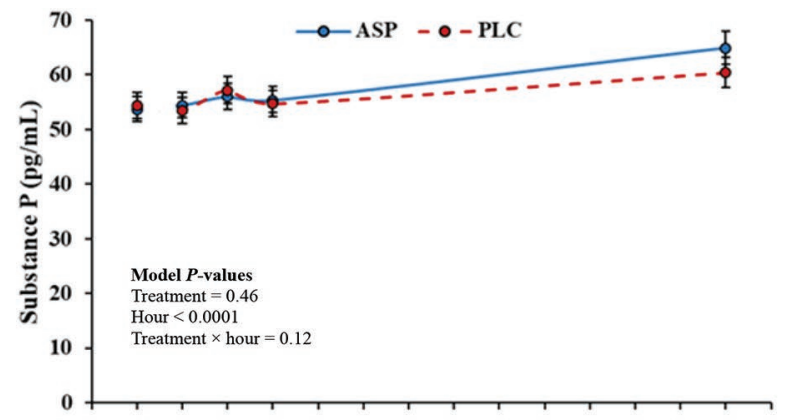

B

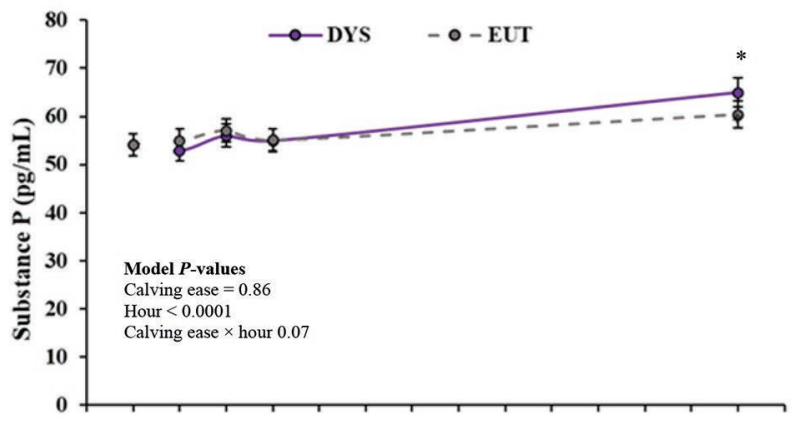

$\mathrm{C}$

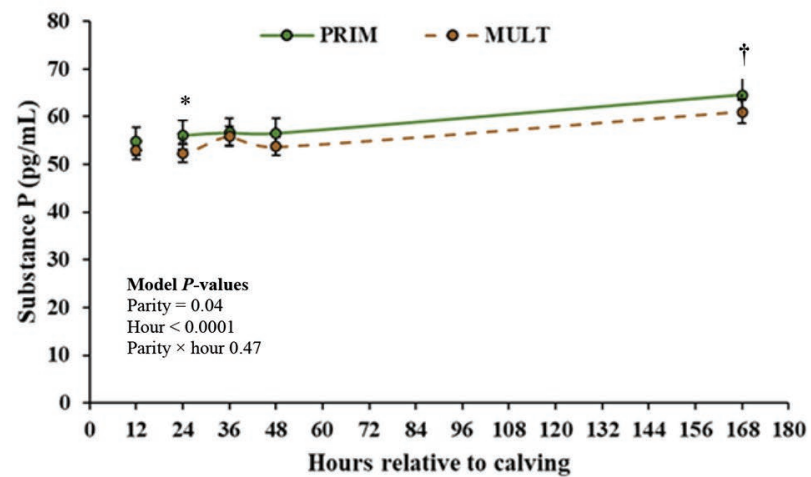

Figure 1. Circulating concentration of substance P (back-transformed geometric mean $\pm 95 \% \mathrm{CI}$ ) at $12,24,36,48$, and $168 \mathrm{~h}$ after parturition in (A) dairy cows treated with acetylsalicylic acid (ASP $\mathrm{n}=76$ ) compared with a placebo (PLC; $\mathrm{n}=76$ ), (B) dairy cows that experienced dystocia (DYS; $\mathrm{n}=76$ ) compared with cows that experienced eutocia (EUT; $\mathrm{n}=76)$, and $(\mathrm{C})$ primiparous (PRIM; $\mathrm{n}=47$ ) and multiparous (MULT; $\mathrm{n}=105$ ) dairy cows. ${ }^{*} P<0.05 ; \dagger 0.05<P$ $\leq 0.10$. $P$-values are from the "slice" option.

$\mu \mathrm{g} / \mathrm{mL} ; \mathrm{PLC}=151.51 \pm 6.71 \mu \mathrm{g} / \mathrm{mL})$. However, there was a tendency for an interaction between treatment and parity $(P=0.08)$, where MULT cows treated with ASP had lower concentration of HP compared with MULT cows treated with PLC $(\mathrm{ASP}=124.33 \pm 6.83$ $\mu \mathrm{g} / \mathrm{mL} ;$ PLC $=143.9 \pm 7.24 \mu \mathrm{g} / \mathrm{mL} ;$ Figure 2$)$. In both groups, HP concentrations reached maximum levels by $36 \mathrm{~h}$ and slightly decreased by $168 \mathrm{~h}$ (Figure 3a). Furthermore, cows that experienced DYS had higher concentrations of HP compared with EUT cows $(P=$ $0.01 ; \mathrm{DYS}=159.17 \pm 5.97 \mu \mathrm{g} / \mathrm{mL} ; \mathrm{EUT}=138.72 \pm$
$6.22 \mu \mathrm{g} / \mathrm{mL}$; Figure 3b). Analysis by parity showed that PRIM cows had higher concentration of HP compared with MULT cows $(P=0.001 ;$ MULT $=134.14 \pm 4.96$ $\mu \mathrm{g} / \mathrm{mL} ;$ PRIM $=163.75 \pm 7.76 \mu \mathrm{g} / \mathrm{mL}$; Figure $3 \mathrm{c})$. In addition, cows that experienced SI-EVT or MU-EVT had higher concentrations of HP $(P=0.005$; NO-EVT $=134.13 \pm 5.95 \mu \mathrm{g} / \mathrm{mL} ;$ SI-EVT $=142.68 \pm 7.32 \mu \mathrm{g} /$ $\mathrm{mL} ; \mathrm{MU}-\mathrm{EVT}=170.03 \pm 9.42 \mu \mathrm{g} / \mathrm{mL}$ ) compared with cows with NO-EVT recorded (Figure 3d).

\section{Circulating Concentration of Cortisol}

No differences in cortisol concentrations were observed between both treatment groups $(P=0.31$, ASP $=20.71 \mathrm{ng} / \mathrm{mL}, 95 \%$ CI: 19.42-22.04; PLC $=19.79$ $\mathrm{ng} / \mathrm{mL}, 95 \%$ CI: $18.42-21.21)$ and calving ease $(P=$ $0.27, \mathrm{DYS}=20.72 \mathrm{ng} / \mathrm{mL}, 95 \%$ CI: $19.41-22.07 ; \mathrm{EUT}$ $=19.74 \mathrm{ng} / \mathrm{mL}, 95 \%$ CI: 18.42-21.11). Regardless of treatment, circulating concentrations of cortisol were at the highest level immediately after parturition, abruptly decreased by $24 \mathrm{~h}$, and continued to gradually decrease thereafter until $7 \mathrm{~d}$ after calving (Figure $4 \mathrm{a}$ ). Analysis by parity revealed that PRIM cows had higher circulating cortisol concentrations than MULT cows $(P$ $=0.0008 ;$ MULT $=18.65 \mu \mathrm{g} / \mathrm{mL}, 95 \%$ CI: $17.63-19.70$; PRIM $=21.92 \mu \mathrm{g} / \mathrm{mL}, 95 \%$ CI: 20.24-23.66; Figure 4b). In addition, circulating cortisol concentrations were higher in SI-EVT and MU-EVT cows compared with cows with NO-EVT recorded $(P=0.0004$; NO$\mathrm{EVT}=17.86 \mu \mathrm{g} / \mathrm{mL}, 95 \%$ CI: 16.66-19.10; SI-EVT $=$ $21.01 \mu \mathrm{g} / \mathrm{mL}, 95 \%$ CI: 19.39-22.68; MU-EVT $=22.01$ $\mu \mathrm{g} / \mathrm{mL}, 95 \%$ CI: 19.92-24.19; Figure 4c).

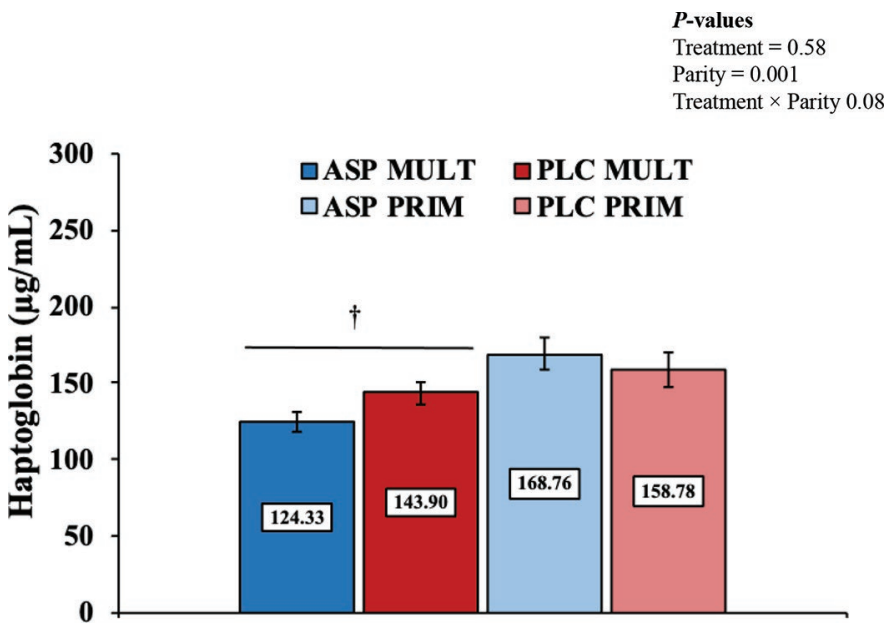

Figure 2. Circulating concentration of haptoglobin (LSM \pm SEM) during the first week after calving in multiparous (ASP MULT; $\mathrm{n}=$ 52 ) and primiparous (ASP PRIM; $\mathrm{n}=24$ ) cows treated with acetylsalicylic acid compared with multiparous (PLC MULT; $\mathrm{n}=53$ ) and primiparous (PLC PRIM; $\mathrm{n}=23$ ) cows treated with a placebo. $\dagger 0.05$ $<P \leq 0.10$. $P$-values are from the "slice" option. 
A

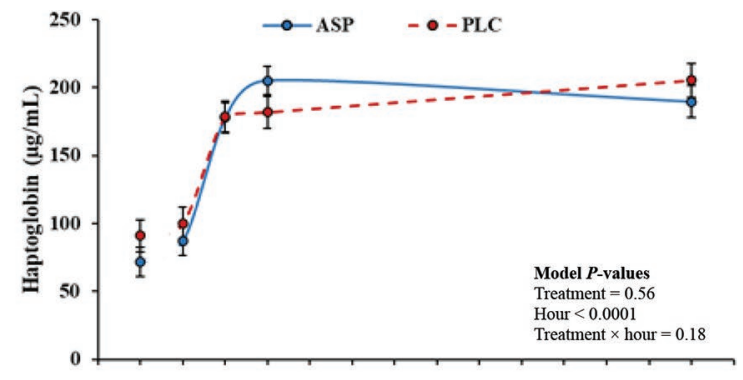

B

C

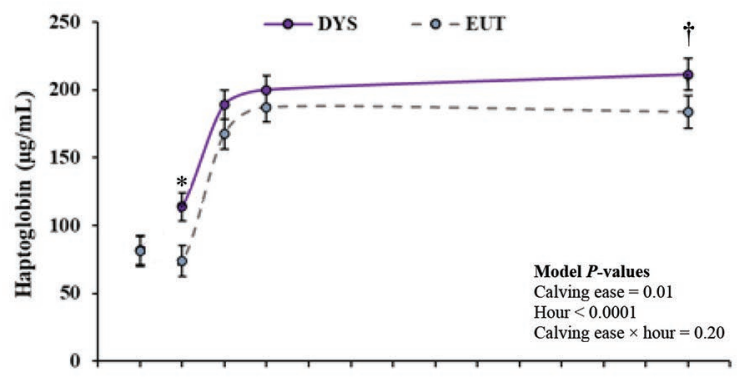

D
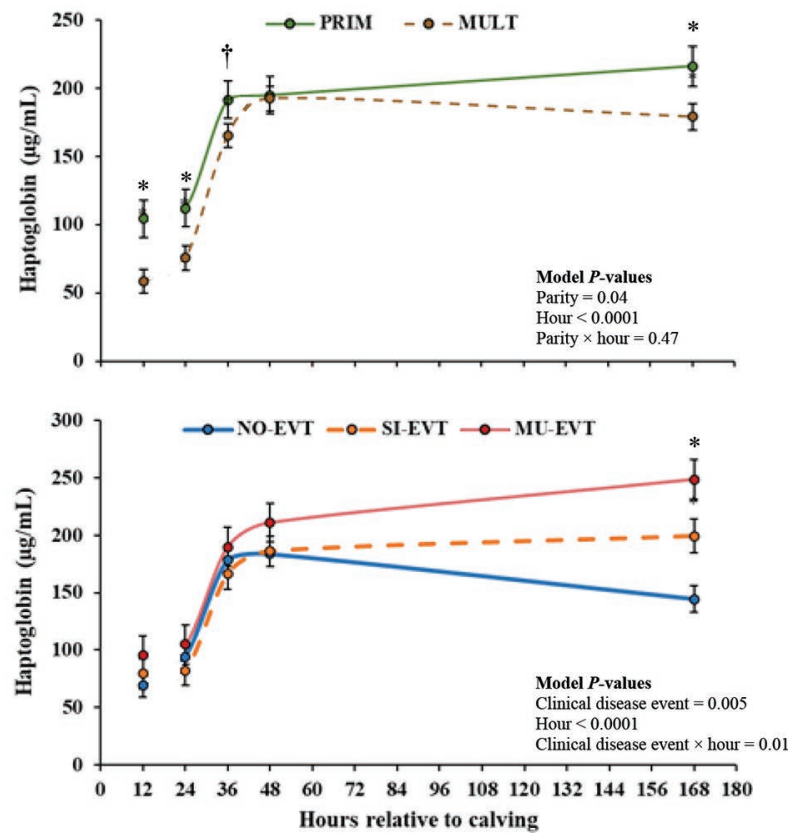

Figure 3. Circulating concentration $s$ of haptoglobin $(\mathrm{LSM} \pm \mathrm{SEM})$ at $12,24,36,48$, and $168 \mathrm{~h}$ after parturition in (A) dairy cows treated with acetylsalicylic acid (ASP; $\mathrm{n}=76$ ) compared with a placebo (PLC; $\mathrm{n}=76)$, (B) dairy cows that experienced dystocia (DYS; $\mathrm{n}=$ 76) compared with cows that experienced eutocia (EUT; $\mathrm{n}=76),(\mathrm{C})$ primiparous (PRIM; $\mathrm{n}=47$ ) and multiparous (MULT; $\mathrm{n}=105$ ) dairy cows, and (D) dairy cows that remained healthy (NO-EVT; $\mathrm{n}=76$ ) or experienced 1 (SI-EVT; $\mathrm{n}=45)$ or more than $1(\mathrm{MU}-\mathrm{EVT} ; \mathrm{n}=31)$ case of clinical disease during the first $60 \mathrm{~d}$ after calving. ${ }^{*} P<0.05$; $\dagger 0.05<P \leq 0.10$. $P$-values are from the "slice" option.

\section{DISCUSSION}

The primary findings of this study are as follows: (1) MULT cows that received ASP tended to have lower HP concentrations than MULT PLC cows; (2) circulat- ing concentrations of SP, HP, and cortisol were higher in PRIM cows compared with MULT cows; (3) animals that experienced DYS had increased concentrations of $\mathrm{HP}$ and SP (at $168 \pm 72 \mathrm{~h}$ after calving) compared with EUT cows; and (4) animals that experienced a single or multiple clinical disease events (i.e., SI-EVT, MU-EVT) had higher circulating concentrations of HP, $\mathrm{SP}$, and cortisol compared with cows that experienced no clinical disease event (i.e., NO-EVT).

In the present study, SP concentrations were lower immediately after parturition, gradually increased, and

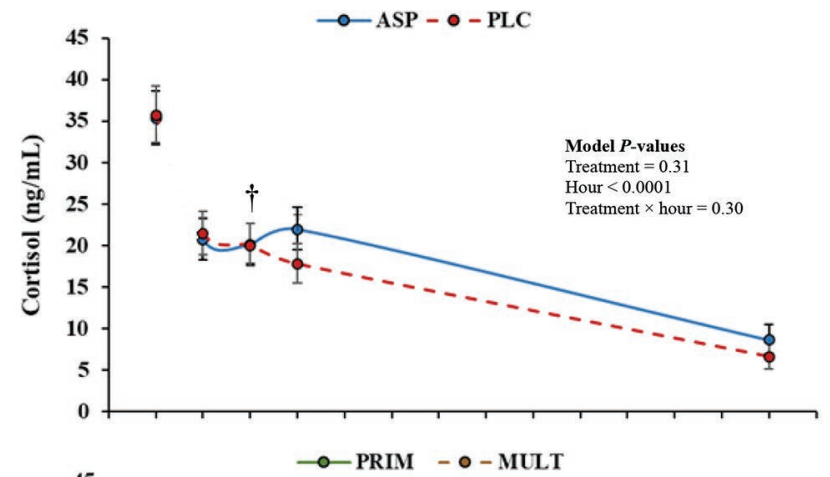

B

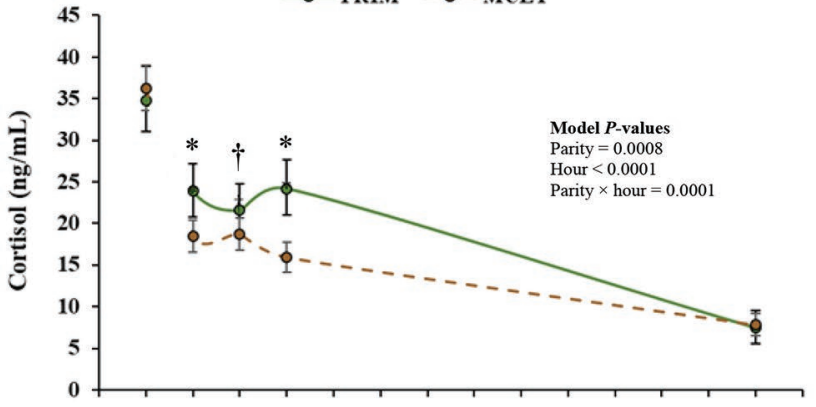

$\mathrm{C}$

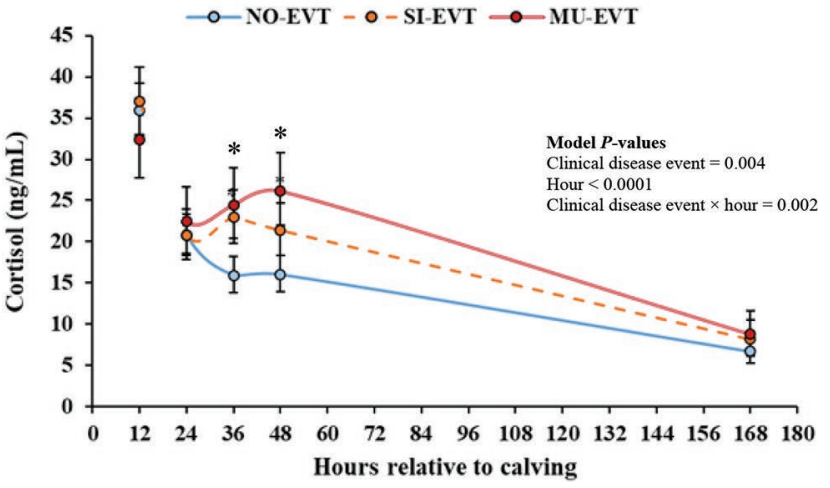

Figure 4. Circulating concentrations of cortisol (back-transformed geometric mean $\pm 95 \% \mathrm{CI}$ ) at $12,24,36,48$, and $168 \mathrm{~h}$ after parturition in (A) dairy cows treated with acetylsalicylic acid (ASP; $\mathrm{n}=76$ ) compared with a placebo (PLC; $\mathrm{n}=76),(\mathrm{B})$ primiparous (PRIM; $\mathrm{n}=$ 47) compared with multiparous (MULT; $\mathrm{n}=105)$ dairy cows, and $(\mathrm{C})$ dairy cows that remained healthy (NO-EVT; $\mathrm{n}=76$ ) or experienced 1 (SI-EVT; $\mathrm{n}=45)$ or more than 1 (MU-EVT; $\mathrm{n}=31$ ) case of clinical disease during the first $60 \mathrm{~d}$ after calving. ${ }^{*} P<0.05 ; \dagger 0.05<P \leq 0.10$. $P$-values are from the "slice" option. 
tended to be higher by 7 DIM regardless of treatment. A previous study reported an upregulation of the SP receptors on the substantia gelatinosa of the spinal cord of rats exposed to chronic pain as opposed to those exposed to short-term pain (Honoré et al., 1999), suggesting that SP may be associated with slow and prolonged inflammation and pain. The NSAID selected for this study (acetylsalicylic acid) and the treatment duration (4 treatments $12 \mathrm{~h}$ apart) should be considered. Due to differences in the chemistry, pharmacokinetics, and pharmacodynamics among NSAID, variations in the anti-inflammatory, analgesic, and duration responses can be observed (Coetzee, 2013). Aspirin is a weak acid that is absorbed slowly through the rumen after oral administration (elimination half-life $=4 \mathrm{~h}$ ) and with a $20 \%$ bioavailability; the recommended dose in cattle is $100 \mathrm{mg} / \mathrm{kg}$ every $12 \mathrm{~h}$ to maintain a systemic concentration within the therapeutic threshold (i.e., $30 \mu \mathrm{g} / \mathrm{L}$; Coetzee, 2013). Although ASP products are widely marketed for treatment of inflammation and pyrexia in cattle, the legality of their use in cattle is controversial because these drugs were never approved by the US Food and Drug Administration for label indications (Coetzee, 2013). For instance, a study that compared treatment with flunixin, meloxicam, and gabapentin in calves undergoing dehorning concluded that intravenous administration of $2.2 \mathrm{mg} / \mathrm{kg}$ flunixin resulted in a greater suppression of prostaglandin $\mathrm{E}_{2}$ in the first $12 \mathrm{~h}$ following dehorning (Fraccaro et al., 2013). Thus, failure to observe a reduction in SP concentrations may at least in part be related to the NSAID and the short treatment duration approach used in the present study. Interestingly, although DYS has been categorized as one of the most painful events in cattle (Huxley and Whay, 2006), our results showed only a tendency for an increase of SP at $168 \pm 72 \mathrm{~h}$ in cows that experienced DYS. As mentioned above, SP may be a better indicator of chronic pain rather than acute pain; thus, a short treatment strategy with ASP may not be sufficient to provide analgesia beyond treatment duration, and longer treatment strategies need to be explored.

Overall, HP concentrations increased from $12 \mathrm{~h}$ to $48 \mathrm{~h}$ after parturition and slightly decreased by 7 DIM. Other authors who reported similar findings observed that HP concentrations were almost undetectable before parturition, increased within $1 \mathrm{~d}$ after parturition, and started to decrease by 7 to 14 DIM (Uchida et al., 1993). In the present study, only ASP MULT cows tended to have lower concentrations of HP compared with PLC MULT cows. The production of HP is stimulated mainly by cytokines (Tizard, 2013) but also by prostaglandins (Shim, 1976). Aspirin decreases the production of prostaglandins by inhibiting COX-1 (Vane and Botting, 2003) and therefore indirectly decreased the secretion of HP and other mediators of inflammation. Supporting the latter, other authors have reported that postpartum treatment with aspirin resulted in decreased concentration of HP in dairy cows (Bertoni et al., 2004). However, it should be noted that HP is a nonspecific marker of inflammation that can be affected by other factors. Other authors have reported no effects on, or an increase of, HP in ASP-treated cows regardless of parity (Carpenter et al., 2016, 2018). As results from this study showed, PRIM cows had higher biomarkers of inflammation, nociception, and stress compared with MULT cows. Similar findings were reported by Pohl et al. (2015), where the authors reported that PRIM cows had higher HP concentration than MULT cows and that DYS did not affect HP concentration in PRIM cows. Thus, a short-duration treatment with a weak anti-inflammatory drug such as ASP may have not been sufficient to decrease inflammation in this group of animals. Further research is warranted to assess the effects of different treatment approaches with ASP on biomarkers of systemic inflammation in high-priority cow groups such as DYS and PRIM animals.

Furthermore, our results showed that cows that experienced DYS had increased concentration of HP compared with cows that experienced EUT. During DYS, the likelihood of damage of the birth canal soft tissues is greater compared with normal births (Farhoodi et al., 2000). Thus, increased circulating concentrations of inflammatory mediators can be expected. A study in sheep (Scott et al., 1992) reported that ewes that experienced DYS and gave birth to a dead lamb had higher concentration of HP than ewes that experienced EUT and had gave birth to a living lamb. However, no differences in HP concentrations were observed between dairy cows that experienced DYS and were treated with meloxicam and untreated DYS controls cows (Newby et al., 2017).

Cortisol concentrations tended to be higher in cows treated with ASP at $48 \mathrm{~h}$ compared with PLC cows. Farney et al. (2013a) reported no differences in circulating cortisol concentrations between cows treated with aspirin and untreated controls. Furthermore, we were not able to detect differences in the concentrations of cortisol between cows with DYS and EUT births. A recent study reported that cows with DYS had increased cortisol concentration immediately after parturition compared with EUT cows; however, in the same study, $1 \mathrm{~h}$ after parturition the cortisol concentration did not differ (Vannucchi et al., 2015). The first sample in our study was collected within $12 \mathrm{~h}$ after parturition, which may help explain the lack of difference in cortisol concentration between DYS and EUT cows. 
Interestingly, in the present study, PRIM cows had higher concentrations HP (i.e., 12, 24, 36, 48, and 168 h) than MULT cows. These results are in agreement with the ones found by Humblet et al. (2006), who also reported higher concentrations of HP in PRIM compared with MULT postpartum cows. Similarly, SP concentrations were higher at 12, 24, 36, 48, and $168 \mathrm{~h}$ in PRIM cows compared with MULT cows. Altogether, PRIM cows seem to experience a more exacerbated inflammatory response than MULT cows. Several studies reported that PRIM cows have higher risk of DYS than MULT cows (Mee, 2008); however, in our study, treatment groups were blocked by parity and calving ease to account for these effects. To the best of our knowledge, no previous studies have assessed SP in postpartum dairy cattle, which makes discussing our findings more challenging. Nevertheless, inflammatory mediators, such as interleukins and prostaglandins, can cause inflammation and pain by local stimulation of nociceptors (Pinho-Ribeiro et al., 2017), indirectly increasing the release of SP and HP. In addition, PRIM cows had higher cortisol concentrations compared with MULT cows regardless of treatment and calving ease. These results agreed with the results observed in HP and SP concentrations in our study, suggesting that PRIM cows experienced a more exacerbated inflammatory reaction after parturition and potentially a greater degree of pain (higher circulating concentration of SP) and stress (higher concentration of cortisol) compared with MULT cows.

In the present study, animals diagnosed with SI-EVT or MU-EVT during the first 60 DIM had higher concentrations of HP and cortisol compared with cows in which NO-EVT was recorded. These results agree with previous research. For instance, Goff and Horst (1997) reported that cows that experienced subclinical and clinical hypocalcemia had higher concentrations of cortisol around calving compared with cows that remained healthy. Similarly, Huzzey et al. (2009) found that cows that experienced metritis during the first weeks after calving had higher concentrations of HP around calving compared with cows that did not have metritis. These results suggest that a higher inflammatory and stress response around calving may increase the susceptibility of cows of becoming ill. In addition to signaling inflammation, regulation of HP production should be considered a metabolic cost to the animal undergoing these events.

\section{CONCLUSIONS}

The results of the present study suggest that treatment with ASP during the first $48 \mathrm{~h}$ after parturition may help decrease inflammation in MULT dairy cows. Furthermore, this study provides scientific evidence that DYS and PRIM cows may experience a greater degree of inflammation and stress early after parturition, suggesting that these group of animals should be considered high-priority groups for monitoring and implementing prevention management strategies, such as anti-inflammatory therapy after calving. Further research is needed to assess different pain management alternatives to alleviate pain in animals that experience DYS during the first week of lactation.

\section{ACKNOWLEDGMENTS}

The authors thank the collaborating dairy farms that participated in the study for providing the facilities and animals necessary to perform this research. Gratitude is also extended to the undergraduate students who collaborated in this study. Special thanks to H. Coetzee and the Veterinary Diagnostic Laboratory (PhAST) at Iowa State University (Ames, IA) for their assistance with substance $\mathrm{P}$ and cortisol laboratory analysis. We also acknowledge the Ohio Dairy Producers Association (Columbus, $\mathrm{OH}$ ) for providing partial funding for this study. The authors have not stated any conflicts of interest.

\section{REFERENCES}

Allen, K. A., J. F. Coetzee, L. N. Edwards-Callaway, H. Glynn, J. Dockweiler, B. KuKanich, H. Lin, C. Wang, E. Fraccaro, M. Jones, and L. Bergamasco. 2013. The effect of timing of oral meloxicam administration on physiological responses in calves after cautery dehorning with local anesthesia. J. Dairy Sci. 96:5194-5205. https: //doi.org/10.3168/jds.2012-6251.

Barragan, A. A., L. Bauman, L. da Costa, J. Velez, J. D. Rozo Gonzalez, G. M. Schuenemann, B. Menichetti, J. Piñeiro, and S. Bas. 2020. Administration of acetylsalicylic acid after parturition in lactating dairy cows under certified organic management: Part I. Milk yield, milk components, activity patterns, fertility, and health. J. Dairy Sci. 103:11697-11712. https://doi.org/10.3168/jds .2020-18388.

Barragan, A. A., J. M. Piñeiro, G. M. Schuenemann, P. J. RajalaSchultz, D. E. Sanders, J. Lakritz, and S. Bas. 2018. Assessment of daily activity patterns and biomarkers of pain, inflammation, and stress in lactating dairy cows diagnosed with clinical metritis. J. Dairy Sci. 101:8248-8258. https://doi.org/10.3168/jds.2018-14510.

Bates, J. L., L. A. Karriker, M. L. Stock, K. M. Pertzborn, L. G. Baldwin, L. W. Wulf, C. J. Lee, C. Wang, and J. F. Coetzee. 2014. Impact of transmammary-delivered meloxicam on biomarkers of pain and distress in piglets after castration and tail docking. PLoS One 9:113678.

Bertoni, G., E. Trevisi, X. Han, and M. Bionaz. 2008. Effects of inflammatory conditions on liver activity in puerperium period and consequences for performance in dairy cows. J. Dairy Sci. 91:3300 3310. https://doi.org/10.3168/jds.2008-0995.

Bertoni, G., E. Trevisi, and F. Piccioli-Cappelli. 2004. Effects of acetyl-salicylate used in post-calving of dairy cows. Vet. Res. Commun. 28:217-219. https://doi.org/10.1023/B:VERC.0000045410 .86004 .03 . 
Carpenter, A. J., C. M. Ylioja, L. K. Mamedova, K. E. Olagaray, and B. J. Bradford. 2018. Effects of early postpartum sodium salicylate treatment on long-term milk, intake, and blood parameters of dairy cows. J. Dairy Sci. 101:1437-1447. https://doi.org/10.3168/ jds.2017-13057.

Carpenter, A. J., C. M. Ylioja, C. F. Vargas, L. K. Mamedova, L. G. Mendonca, J. F. Coetzee, L. C. Hollis, R. Gehring, and B. J. Bradford. 2016. Hot topic: Early postpartum treatment of commercial dairy cows with nonsteroidal antiinflammatory drugs increases whole-lactation milk yield. J. Dairy Sci. 99:672-679. https://doi .org/10.3168/jds.2015-10048.

Coetzee, J. F. 2011. A review of pain assessment techniques and pharmacological approaches to pain relief after bovine castration: Practical implications for cattle production within the United States. Appl. Anim. Behav. Sci. 135:192-213. https://doi.org/10.1016/j applanim.2011.10.016.

Coetzee, J. F. 2013. A review of analgesic compounds used in food animals in the United States. Vet. Clin. North Am. Food Anim. Pract. 29:11-28. https://doi.org/10.1016/j.cvfa.2012.11.008.

DeVane, C. L. 2001. Substance P: A new era, a new role. Pharmacotherapy 21:1061-1069. https://doi.org/10.1592/phco.21.13.1061 .34612 .

Eckersall, P. D., F. J. Young, C. McComb, C. J. Hogarth, S. Safi, J. L. Fitzpatrick, A. M. Nolan, A. Weber, and T. McDonald. 2001. Acute phase proteins in serum and milk from dairy cows with clinical mastitis. Vet. Rec. 148:35-41. https://doi.org/10.1136/vr .148 .2 .35 .

Farhoodi, M., I. Nowrouzian, P. Hovareshti, M. Bolourchi, and M. G. Nadalian. 2000. Factors associated with rectovaginal injuries in Holstein dairy cows in a herd in Tehran, Iran. Prev. Vet. Med. 46:143-148. https://doi.org/10.1016/S0167-5877(00)00129-X.

Farney, J. K., L. K. Mamedova, J. F. Coetzee, B. KuKanich, L. M. Sordillo, S. K. Stoakes, J. E. Minton, L. C. Hollis, and B. J. Bradford. 2013a. Anti-inflammatory salicylate treatment alters the metabolic adaptations to lactation in dairy cattle. Am. J. Physiol. Regul. Integr. Comp. Physiol. 305:R110-R117. https://doi.org/10 .1152/ajpregu.00152.2013.

Farney, J. K., L. K. Mamedova, J. F. Coetzee, J. E. Minton, L. C. Hollis, and B. J. Bradford. 2013b. Sodium salicylate treatment in early lactation increases whole-lactation milk and milk fat yield in mature dairy cows. J. Dairy Sci. 96:7709-7718. https://doi.org/10 .3168/jds.2013-7088.

Fraccaro, E., J. F. Coetzee, R. Odore, L. N. Edwards-Callaway, B. Kukanich, P. Badino, L. Bertolotti, H. Glynn, J. Dockweiler, K. Allen, and L. Bergamasco. 2013. A study to compare circulating flunixin, meloxicam and gabapentin concentrations with prostaglandin $\mathrm{E}_{2}$ levels in calves undergoing dehorning. Res. Vet. Sci. 95:204-211. https://doi.org/10.1016/j.rvsc.2013.01.018.

Goff, J. P., and R. L. Horst. 1997. Physiological changes at parturition and their relationship to metabolic disorders. J. Dairy Sci. 80:1260-1268. https://doi.org/10.3168/jds.S0022-0302(97)76055 -7 .

Honoré, P., P. M. Menning, S. D. Rogers, M. L. Nichols, A. I. Basbaum, J.-M. Besson, and P. W. Mantyh. 1999. Spinal substance P receptor expression and internalization in acute, short-term, and long-term inflammatory pain states. J. Neurosci. 19:7670-7678. https://doi.org/10.1523/JNEUROSCI.19-17-07670.1999.

Humblet, M.-F., H. Guyot, B. Boudry, F. Mbayahi, C. Hanzen, F. Rollin, and J.-M. Godeau. 2006. Relationship between haptoglobin, serum amyloid $\mathrm{A}$, and clinical status in a survey of dairy herds during a 6-month period. Vet. Clin. Pathol. 35:188-193. https:// doi.org/10.1111/j.1939-165X.2006.tb00112.x.

Huxley, J. N., and H. R. Whay. 2006. Current attitudes of cattle practitioners to pain and the use of analgesics in cattle. Vet. Rec. 159:662-668. https://doi.org/10.1136/vr.159.20.662.

Huzzey, J. M., T. F. Duffield, S. J. LeBlanc, D. M. Veira, D. M. Weary, and M. A. G. Von Keyserlingk. 2009. Short communication: Haptoglobin as an early indicator of metritis. J. Dairy Sci. 92:621-625. https://doi.org/10.3168/jds.2008-1526.

Iwersen, M., U. Falkenberg, R. Voigtsberger, D. Forderung, and W. Heuwieser. 2009. Evaluation of an electronic cowside test to detect subclinical ketosis in dairy cows. J. Dairy Sci. 92:2618-2624. https: //doi.org/10.3168/jds.2008-1795.

Kvidera, S. K., M. J. Dickson, M. Abuajamieh, D. B. Snider, M. V. S. Fernandez, J. S. Johnson, A. F. Keating, P. J. Gorden, H. B. Green, K. M. Schoenberg, and L. H. Baumgard. 2017a. Intentionally induced intestinal barrier dysfunction causes inflammation, affects metabolism, and reduces productivity in lactating Holstein cows. J. Dairy Sci. 100:4113-4127. https://doi.org/10.3168/jds 2016-12349.

Kvidera, S. K., E. A. Horst, M. Abuajamieh, E. J. Mayorga, M. V. S. Fernandez, and L. H. Baumgard. 2017b. Glucose requirements of an activated immune system in lactating Holstein cows. J. Dairy Sci. 100:2360-2374. https://doi.org/10.3168/jds.2016-12001.

Lombard, J. E., F. B. Garry, S. M. Tomlinson, and L. P. Garber. 2007. Impacts of dystocia on health and survival of dairy calves. J. Dairy Sci. 90:1751-1760. https://doi.org/10.3168/jds.2006-295.

Mee, J. F. 2008. Prevalence and risk factors for dystocia in dairy cattle: A review. Vet. J. 176:93-101. https://doi.org/10.1016/j.tvjl .2007.12.032.

Montgomery, S. R., L. K. Mamedova, M. Zachut, G. Kra, S. Häussler, M. Vaughn, J. Gonzalez, and B. J. Bradford. 2019. Effects of sodium salicylate on glucose kinetics and insulin signaling in postpartum dairy cows. J. Dairy Sci. 102:1617-1629.

Newby, N. C., K. E. Leslie, H. D. P. Dingwell, D. F. Kelton, D. M. Weary, L. Neuder, S. T. Millman, and T. F. Duffield. 2017. The effects of periparturient administration of flunixin meglumine on the health and production of dairy cattle. J. Dairy Sci. 100:582-587. https://doi.org/10.3168/jds.2016-11747.

Noakes, D. E., T. J. Parkinson, G. C. W. England, and G. H. Arthur. 2001. Parturition and the Care of Parturient Animals. WB Saunders, Oxford, UK.

Norman, J. E., S. Bollapragada, M. Yuan, and S. M. Nelson. 2007. Inflammatory pathways in the mechanism of parturition. BMC Pregnancy Childbirth 7(Supp. 1):S7. https://doi.org/10.1186/ 1471-2393-7-S1-S7.

Pinho-Ribeiro, F. A., W. A. Verri Jr., and I. M. Chiu. 2017. Nociceptor sensory neuron-immune interactions in pain and inflammation. Trends Immunol. 38:5-19. https://doi.org/10.1016/j.it.2016 .10.001.

Pohl, A., O. Burfeind, and W. Heuwieser. 2015. The associations between postpartum serum haptoglobin concentration and metabolic status, calving difficulties, retained fetal membranes, and metritis J. Dairy Sci. 98:4544-4551.

Santos, J. E. P., R. S. Bisinotto, E. S. Ribeiro, F. S. Lima, L. F. Greco, C. R. Staples, W. W. Thatcher, M. F. Smith, M. C. Lucy, and J. L. Pate. 2011. Applying nutrition and physiology to improve reproduction in dairy cattle. Reprod. Domest. Rumin. VII:387-403.

Scott, P. R., L. D. Murray, and C. D. Penny. 1992. A preliminary study of serum haptoglobin concentration as a prognostic indicator of ovine dystocia cases. Br. Vet. J. 148:351-355. https://doi.org/10 .1016/0007-1935(92)90087-H

Sheldon, I. M., E. J. Williams, A. N. Miller, D. M. Nash, and S. Herath. 2008. Uterine diseases in cattle after parturition. Vet. J. 176:115-121. https://doi.org/10.1016/j.tvjl.2007.12.031.

Shim, B.-S. 1976. Increase in serum haptoglobin stimulated by prostaglandins. Nature 259:326-327.

Smith, B. I., J. Kauffold, and L. Sherman. 2010. Serum haptoglobin concentrations in dairy cattle with lameness due to claw disorders. Vet. J. 186:162-165. https://doi.org/10.1016/j.tvjl.2009.08.012.

Sordillo, L. M., G. M. Pighetti, and M. R. Davis. 1995. Enhanced production of bovine tumor necrosis factor- $\alpha$ during the periparturient period. Vet. Immunol. Immunopathol. 49:263-270. https:/ /doi.org/10.1016/0165-2427(95)05465-0.

Stock, M. L., S. L. Baldridge, D. Griffin, and J. F. Coetzee. 2013. Bovine dehorning: Assessing pain and providing analgesic management. Vet. Clin. North Am. Food Anim. Pract. 29:103-133. https: //doi.org/10.1016/j.cvfa.2012.11.001.

Theurer, M. E., D. E. Amrine, and B. J. White. 2013. Remote noninvasive assessment of pain and health status in cattle. Vet. Clin North Am. Food Anim. Pract. 29:59-74. https://doi.org/10.1016/ j.cvfa.2012.11.011. 
Tizard, I. R. 2013. Veterinary Immunology. Elsevier Health Sciences, Amsterdam, the Netherlands.

Trevisi, E., M. Amadori, S. Cogrossi, E. Razzuoli, and G. Bertoni. 2012. Metabolic stress and inflammatory response in high-yielding, periparturient dairy cows. Res. Vet. Sci. 93:695-704. https://doi .org/10.1016/j.rvsc.2011.11.008.

Uchida, E., N. Katoh, and K. Takahashi. 1993. Appearance of haptoglobin in serum from cows at parturition. J. Vet. Med. Sci. 55:893894. https://doi.org/10.1292/jvms.55.893.

Van Engen, N. K., M. L. Stock, T. Engelken, R. C. Vann, L. W. Wulf, L. A. Karriker, W. D. Busby, J. Lakritz, A. J. Carpenter, B. J. Bradford, W. H. Hsu, C. Wang, and J. F. Coetzee. 2014. Impact of oral meloxicam on circulating physiological biomarkers of stress and inflammation in beef steers after long-distance transportation. J. Anim. Sci. 92:498-510. https://doi.org/10.2527/jas.2013-6857.
Van Nuffel, A., I. Zwertvaegher, L. Pluym, S. Van Weyenberg, V. M. Thorup, M. Pastell, B. Sonck, and W. Saeys. 2015. Lameness detection in dairy cows: Part 1 . How to distinguish between non-lame and lame cows based on differences in locomotion or behavior. Animals (Basel) 5:838-860. https://doi.org/10.3390/ani5030387.

Vane, J. R., and R. M. Botting. 2003. The mechanism of action of aspirin. Thromb. Res. 110:255-258. https://doi.org/10.1016/S0049 -3848(03)00379-7.

Vannucchi, C. I., J. A. Rodrigues, L. C. G. Silva, C. F. Lúcio, G. L. Veiga, P. V. Furtado, C. A. Oliveira, and M. Nichi. 2015. Association between birth conditions and glucose and cortisol profiles of periparturient dairy cows and neonatal calves. Vet. Rec. 176:358. https://doi.org/10.1136/vr.102862 